\title{
A humidity-controlled fast integrated mobility spectrometer (HFIMS) for rapid measurements of particle hygroscopic growth
}

Tamara Pinterich et al.

Correspondence to: Jian Wang (jian@bnl.gov)

The copyright of individual parts of the supplement might differ from the CC BY 4.0 License. 


\section{Supplemental Information}

\section{S1 WFIMS Configuration}

\begin{tabular}{l|l|l}
$Q_{\mathrm{a}}$ & Aerosol Flow & $0.3 \mathrm{l} / \mathrm{min}$ \\
\hline$Q_{\mathrm{sh}}$ & Sheath Flow & $16.2 \mathrm{l} / \mathrm{min}$ \\
\hline$\Delta \mathrm{T}_{\mathrm{con}}$ & Conditioner & $-12{ }^{\circ} \mathrm{C}$ \\
\hline$\Delta \mathrm{T}_{\text {ini }}$ & Initiator & $+28^{\circ} \mathrm{C}$ \\
\hline$\Delta \mathrm{T}_{\text {mod }}$ & Moderator & $-10{ }^{\circ} \mathrm{C}$ \\
\hline$a$ & Distance between separator electrodes & $0.91 \mathrm{~cm}$ \\
\hline$b$ & Width of flow channel = Entrance slit width & $12.70 \mathrm{~cm}$ \\
\hline & Entrance slit gap & $0.25 \mathrm{~mm}$ \\
\hline$l_{\mathrm{s}}$ & Separator length & $14.18 \mathrm{~cm}$ \\
\hline$x_{\text {view }}$ & Range in x-direction of viewing area & $0.18 \mathrm{~cm}-0.73 \mathrm{~cm}$ \\
\hline$y_{\text {view }}$ & Range in y-direction of viewing area & $-3.50 \mathrm{~cm}-+3.50 \mathrm{~cm}$
\end{tabular}

\section{S2 HFIMS configuration during laboratory characterization}

\begin{tabular}{|c|c|c|c|c|}
\hline & $V$ & Separating Voltage & \multicolumn{2}{|l|}{$1000 \mathrm{~V}$} \\
\hline$\sum$ & $D_{\mathrm{p}, \min }$ & Minimum wet particle diameter & \multicolumn{2}{|l|}{$44.8 \mathrm{~nm}$} \\
\hline & $D_{\mathrm{p}, \max }$ & Maximum wet particle diameter & \multicolumn{2}{|l|}{$160.8 \mathrm{~nm}$} \\
\hline \multirow{5}{*}{ 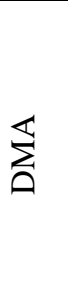 } & Type & \multicolumn{3}{|l|}{ NDMA } \\
\hline & $Q_{\mathrm{a}}$ & Aerosol Flow & \multicolumn{2}{|l|}{$1.3 \mathrm{l} / \mathrm{min}$} \\
\hline & $Q_{\text {sh }}$ & Sheath Flow & \multicolumn{2}{|l|}{$13 \mathrm{l} / \mathrm{min}$} \\
\hline & $V$ & Classifying Voltage & \multicolumn{2}{|l|}{$5332 \mathrm{~V}$} \\
\hline & $D_{\mathrm{p}, 0}$ & Dry Particle Diameter & \multicolumn{2}{|l|}{$50 \mathrm{~nm}$} \\
\hline \multirow{4}{*}{ 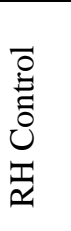 } & & & Deliquescence & Efflorescence \\
\hline & $\mathrm{RH}_{\mathrm{a}}$ & Aerosol RH & \multirow{3}{*}{$20 \%-90 \%$} & $85 \%$ \\
\hline & $\mathrm{RH}_{\mathrm{sh}}$ & Sheath RH & & $18.8 \%-79.9 \%$ \\
\hline & $\mathrm{RH}$ & Mixed RH & & $20 \%-80 \%$ \\
\hline \multirow{2}{*}{$\sum_{I}^{\infty}$} & $D_{\mathrm{p}, \text { min }} / D_{\mathrm{p}, 0}$ & Minimum Growth Factor & \multicolumn{2}{|l|}{0.9} \\
\hline & $D_{\mathrm{p}, \max } / D_{\mathrm{p}, 0}$ & Maximum Growth Factor & \multicolumn{2}{|l|}{3.2} \\
\hline $\mathrm{CPC}$ & $Q_{\mathrm{a}}$ & Aerosol Flow & \multicolumn{2}{|l|}{$1 \mathrm{l} / \mathrm{min}$} \\
\hline
\end{tabular}




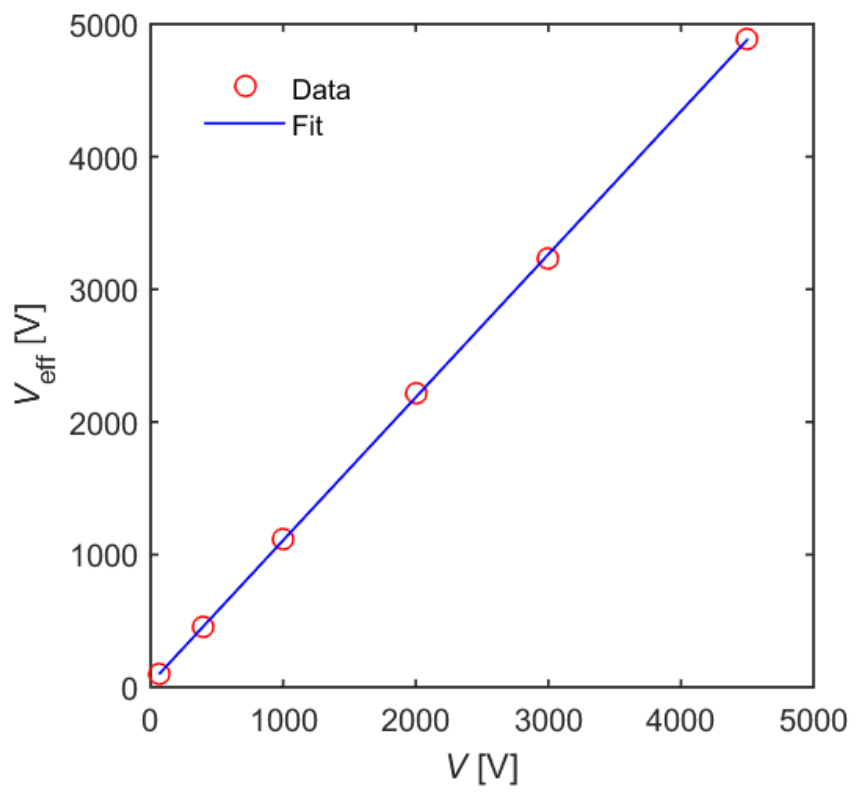

Figure S1 Calibration curve for the separator voltage of HFIMS. $V$ and $V_{\text {eff }}$ are applied and effective voltage, respectively.

To account for non-idealities of the electric field between WFIMS separator electrodes, the applied voltages $V$ were replaced with effective voltages $V_{\text {eff }}$ when calculating instrument response mobilities $Z_{\mathrm{p}}^{*}$. The $V_{\text {eff }}$ values were derived from WFIMS measurements of DMA classified particles at low RH $(<10 \%)$. For particles classified with DMA centroid mobilities $Z_{\mathrm{p}, \mathrm{DMA}}$ ranging from $9.2 \cdot 10^{-7} \mathrm{~m}^{2} / \mathrm{Vs}$ at $V=70 \mathrm{~V}$ to $2.3 \cdot 10^{-8} \mathrm{~m}^{2} / \mathrm{Vs}$ at $V=4500 \mathrm{~V}$ (see Sect. S4), the values of $V_{\text {eff }}$ (see Eq. (2)) were found such that $Z_{\mathrm{p}}^{*}$ calculated based on measured particle positions (Eq. (1)) and $V_{\text {eff }}$ will reproduce $Z_{\mathrm{p}, \text { DMA. }}$. Resulting effective voltages are plotted as a function of applied voltages in Fig. S1 (open red circles). It can be seen that for the entire applied voltage range, i. e. $70-4500 \mathrm{~V}, V_{\text {eff }}$ exceeds $V$, and the relationship between $V_{\text {eff }}$ and $V$ is linear. Hence following parametrization was used to obtain a general expression for $V_{\text {eff }}$ based on applied voltages:

$V_{\text {eff }}(V)=a(V+b)$.

By fitting $V_{\text {eff }}$ derived from measurements parameters $a$ and $b$ were determined as 1.1 and $27.8 \mathrm{~V}$, respectively. The $27.8 \mathrm{~V}$ represent a constant offset, and might be due to an offset of the WFIMS HV power supply, which has a full scale of $10000 \mathrm{~V}$. The scaling factor $a$ might be related to voltage dependent edge effects of the electric field. 
S4 HFIMS Configuration during ambient tests

\begin{tabular}{|c|c|c}
$\begin{array}{c}\text { Separating Voltage } \\
{[\mathrm{V}]}\end{array}$ & $\begin{array}{c}\text { Minimum wet particle diameter } \\
D_{\mathrm{p}, \min }[\mathrm{nm}]\end{array}$ & $D_{\mathrm{p}, \max }[\mathrm{nm}]$ \\
\hline 70 & 12.8 & 40.4 \\
400 & 28.1 & 94.1 \\
\hline 1000 & 44.8 & 160.8 \\
\hline 2000 & 64.9 & 253.3 \\
\hline 3000 & 81.3 & 338.3 \\
\hline 4500 & 102.5 & 461.4 \\
\hline 4500 & 102.5 & 461.4 \\
\hline
\end{tabular}

\begin{tabular}{|c|c|c|c|}
\hline \multirow{10}{*}{ 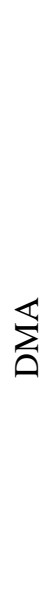 } & $Q_{\mathrm{a}}$ & Aerosol Flow & $0.3 \mathrm{l} / \mathrm{min}$ \\
\hline & $Q_{\mathrm{sh}}$ & Sheath Flow & $31 / \mathrm{min}$ \\
\hline & Type & Classifying Voltage [V] & Dry Particle Diameter [nm] \\
\hline & NDMA & 115 & 15 \\
\hline & NDMA & 599 & 35 \\
\hline & NDMA & 1181 & 50 \\
\hline & NDMA & 2202 & 70 \\
\hline & NDMA & 4923 & 110 \\
\hline & LDMA & 1148 & 165 \\
\hline & LDMA & 2355 & 265 \\
\hline
\end{tabular}

\begin{tabular}{|c|c|c|c|}
\hline \multirow{3}{*}{ 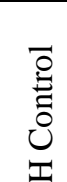 } & $\mathrm{RH}_{\mathrm{a}}$ & Aerosol RH & \multirow{3}{*}{$85 \%$} \\
\hline & $\mathrm{RH}_{\mathrm{sh}}$ & Sheath RH & \\
\hline & RH & Mixed RH & \\
\hline
\end{tabular}

\begin{tabular}{|c|c|c|c}
\hline$D_{\mathrm{p}, 0}[\mathrm{~nm}]$ & $\begin{array}{c}\text { Minimum Growth Factor } \\
\left(D_{\mathrm{p}, \min } / D_{\mathrm{p}, 0}\right)\end{array}$ & $\begin{array}{c}\text { Maximum Growth Factor } \\
\left(D_{\mathrm{p}, \max } / D_{\mathrm{p}, 0}\right)\end{array}$ \\
\hline 15 & 0.9 & 2.7 \\
\hline 35 & 0.8 & 2.7 \\
\hline 50 & 0.9 & 3.2 \\
\hline 70 & 0.9 & 3.6 \\
\hline 110 & 0.7 & 3.1 \\
\hline 165 & 0.6 & 2.7 \\
\hline 265 & 0.4 & 1.7 \\
\hline
\end{tabular}

\begin{tabular}{c|c|cc}
\hline CPC & $Q_{\mathrm{a}}$ & Aerosol Flow & $1.01 / \mathrm{min}$ \\
\hline & $Q_{\operatorname{Tr}}$ & Transport Flow & $5.41 / \mathrm{min}$
\end{tabular}



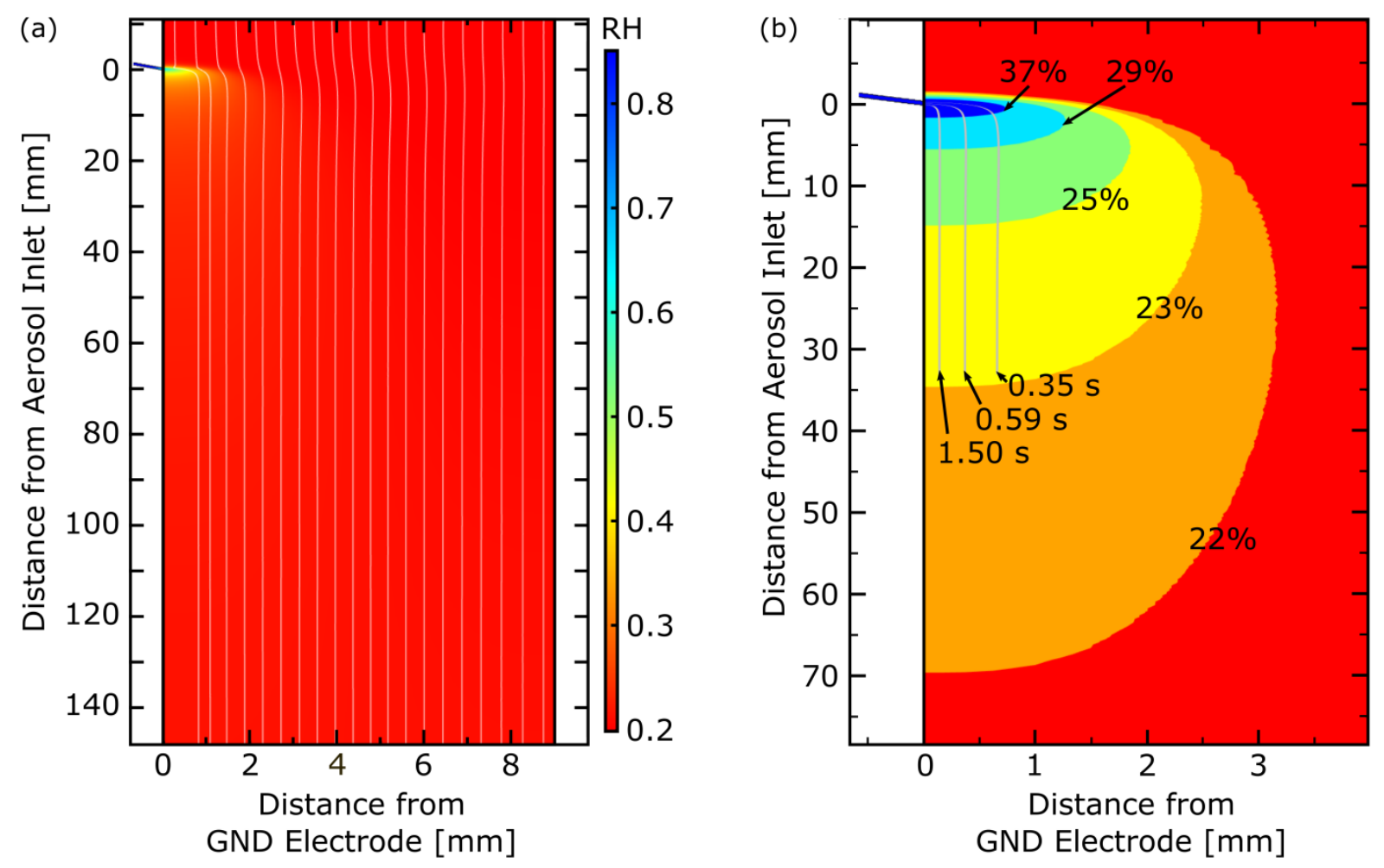

Figure S2 (a) Offset electrode used in HFIMS, with aerosol inlet on left. (b) Enlargement of inlet region showing relative humidity profiles when entering aerosol is at $85 \%$ and sheath flow at $20 \%$.

The single high voltage electrode was configured with an offset such that the high voltage region begins slightly downstream (32 $\mathrm{mm}$ ) of the introduction of aerosol into the mobility separator. This allows the sheath flow to provide the final humidity conditioning of the aerosol flow prior to mobility classification as the aerosol flow is just $2 \%$ of the total flow. The electrode offset is illustrated in Fig. S2 (a), where the dimension along the width of the channel is shown enlarged relative to the length. Fig. S2 (b) shows modeled relative humidity profiles at the aerosol inlet obtained using COMSOL Multiphysics®, a numerical modeling package. For instance when the entering aerosol is at $85 \% \mathrm{RH}(0.3 \mathrm{l} / \mathrm{min})$ and the entering sheath flow is at $20 \%(16.2$ 1/min) then at the $32 \mathrm{~mm}$ position downstream where the mobility separation begins, the aerosol has reached $23 \% \mathrm{RH}$, within $1.8 \%$ of the desired RH $21.2 \%=(0.3 \cdot 85 \%+16.2 \cdot 20 \%) /(0.3+16.2)$ after a complete mixing of aerosol and sheath flow. The equilibration time for the aerosol ranges from 0.35 to $1.50 \mathrm{~s}$, as shown Fig. S2 (b). This approach allows the final RH adjustment of the aerosol to be made within the WFIMS system. 